\title{
Encontros e Desencontros entre Psicologia e Política: Formando, Deformando e Transformando Profissionais de Saúde
}

Convergences and Divergences Between Psychology And Politics:
Forming, Deforming and Transforming Health Professionals

Encuentros y Desencuentros entre Psicología y Política: Formando, Deformando y Transformando Profesionales de Salud

Carolina dos Reis \&

Neuza Maria de

Fátima Guareschi

Universidade Federal

do Rio Grande do Sul
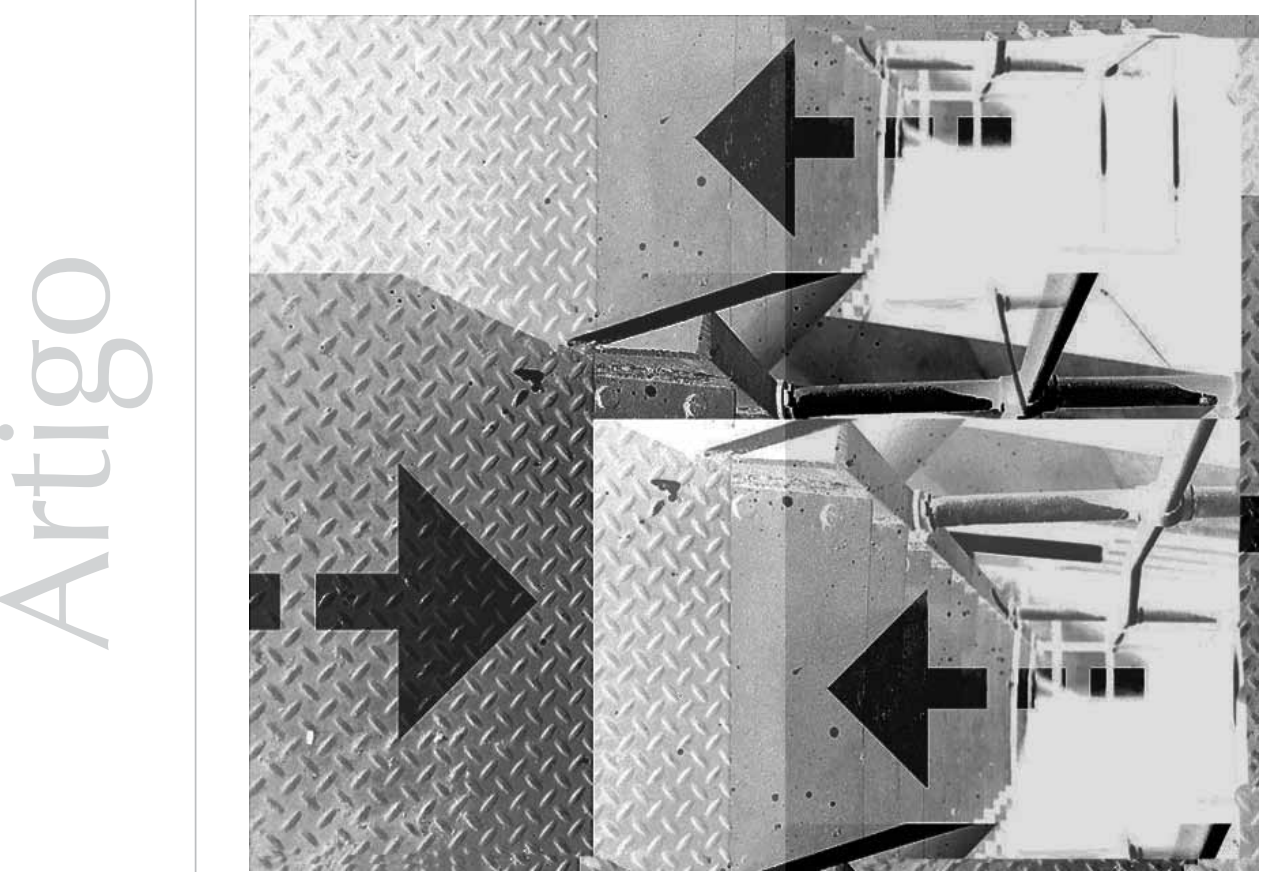
Afetações

- Mas o teu estágio é do quê, mesmo?

- Comunitária.

- Ah! (Pausa). Mas o que exatamente vocês fazem lá no Conselho?

- Diversas coisas, a gente participa, por

exemplo, de uma instância de Controle Social, na Comissão de...

- Ah, aquela coisa da fiscalização que o CRP faz dos psicólogos.

- Não! A gente participa do Controle Social do Município,

no Conselho

Municipal de

Saúde. O Controle

Social é como uma

fiscalização, só

que é a população

pedindo uma

prestação de contas

para o gestor das

ações realizadas na

saúde.

- Tá, mas o que isso tem a ver com a Psicologia?

\footnotetext{
1 Trecho de um diálogo entre uma das estagiárias e um aluno da graduação, representativo de conversas vivenciadas com outros tantos estudantes durante o período de estágio.
}

Resumo: Este artigo tem por objetivo realizar uma discussão sobre a dicotomização entre Psicologia e política na formação e nas práticas desses campos de saber. Essa reflexão se desenvolve a partir da experiência de estágio curricular em Psicologia realizado junto ao Centro de Referência Técnica em Psicologia e Políticas Públicas (CREPOP), no Conselho Regional de Psicologia do Rio Grande do Sul. Através de atividades realizadas, principalmente das ações do Controle Social, no Conselho Municipal de Saúde de Porto Alegre, discutimos a construção e o ensino do conhecimento da Psicologia fundamentado no pensamento foucaultiano sobre saber, relações de poder e discurso para visualizarmos a impossibilidade de a formação e de as práticas em Psicologia continuarem pautadas na perspectiva da ciência da Modernidade. Evidenciamos a necessidade, a partir da demanda da formação do profissional da saúde dessa área para o SUS, do reconhecimento das práticas psicológicas como ações políticas e da reflexão sobre o modo como elas incidem na vida dos sujeitos.

Palavras-chave: Política. Formação do psicólogo. Controle social. Centro de Referência em Psicologia e Políticas Públicas - CREPOP.

Abstract: This article aims at discussing the dichotomization between psychology and politics in both education and practices in these knowledge fields. This reflection has developed from the curricular training in psychology at the Center of Technical Reference in Psychology and Public Policies, in the Regional Psychology Association, in Rio Grande do Sul. Through the activities performed, mainly in actions of Social Control at the Municipal Health Association of Porto Alegre, we discussed the construction and teaching of knowledge in psychology, as founded on the foucauldian thought about knowledge, power relations and discourse to make evident the impossibility of education and practices in psychology be guided according to the perspective of science advocated in Modernity. We have shown the necessity, from the demand in the education of health professionals in this area for SUS, of acknowledging psychological practices as political actions and the need of reflection on the way they influence the subjects' lives.

Keywords: Politics. Education in psychology. Social control. Centro de Referência em Psicologia e Políticas Públicas - CREPOP.

Resumen: Este artículo tiene por objetivo realizar una discusión sobre la dicotomización entre Psicología y política en la formación y en las prácticas de esos campos de saber. Esa reflexión se desarrolla a partir de la experiencia de prácticas curricular en Psicología realizado junto al Centro de Referencia Técnica en Psicología y Políticas Públicas (CREPOP), en el Consejo Regional de Psicología de Rio Grande do Sul. A través de actividades realizadas, principalmente de las acciones del Control Social, en el Consejo Municipal de Salud de Porto Alegre, discutimos la construcción y la enseñanza del conocimiento de la Psicología fundamentado en el pensamiento foucaultiano sobre saber, relaciones de poder y discurso para visualizar la imposibilidad de la formación y de las prácticas en Psicología continuar pautadas en la perspectiva de la ciencia de la Modernidad. Evidenciamos la necesidad, a partir de la demanda de la formación del profesional de la salud de esa área para el SUS, del reconocimiento de las prácticas psicológicas como acciones políticas y de la reflexión sobre el modo como ellas inciden en la vida de los sujetos.

Palabras clave: Política. Formación del psicólogo. Control social. Centro de Referencia en Psicología y Políticas Públicas - CREPOP.

A Psicologia, como campo do conhecimento, faz parte do projeto de ciência inaugurado pela Modernidade que traz consigo a crença em naturezas e essências, nas verdades universais, na objetividade do mundo e na existência dos objetos em si. Nesse sentido, a Psicologia também acreditou e acredita ser possível a apreensão da realidade de forma imparcial, primando pela razão em detrimento da sensação (Coimbra \& Nascimento, 2001). O efeito que se produziu foi a emergência de determinados saberes, que se tornam dominantes por se dizerem científicos e, portanto, mais verdadeiros quando comparados a outros conhecimentos que são apontados como não científicos, incompletos ou impregnados pela subjetividade, e que sofrem, com isso, uma desqualificação (Coimbra \& Nascimento, 2001).

Analisando a busca pela cientificidade, Nascimento, Manzini e Bocco (2006) afirmam que a Psicologia, como área do conhecimento e de formação, vai se constituir a partir de dois campos: o da observação e o da clínica, 
ambos sustentados em uma perspectiva de neutralidade a-histórica. Foi na tentativa de um status de objetividade que durante muito tempo se primou, na formação em Psicologia, por uma suposta impessoalidade do psicólogo, sendo a neutralidade considerada condição fundamental para as práticas desse profissional para evitar interferências supostamente inconscientes no seu trabalho, especialmente na área clínica.

Diante dessa visão essencialista de mundo e de neutralidade profissional é que foram se construindo as oposições e os binarismos que separam sujeito e objeto, indivíduo e coletivo, interior e exterior, assim como Psicologia e política. Essa divisão dá a ideia de que essas categorias são diametralmente opostas, distantes, que possuem uma natureza intrínseca que lhes atribui um caráter de previsibilidade. No intuito de manter a cientificidade, a Psicologia deve, então, resguardar-se das misturas e das impurezas, não tendo lugar, portanto, ao lado da política. Uma vez entendida como ciência, a Psicologia nada tem a ver com política (Coimbra \& Nascimento, 2001).

Dimenstein (2001), em uma discussão que realiza sobre as práticas da Psicologia no SUS, fundamenta essa dicotomização entre Psicologia e política quando diz que:

Historicamente, a Psicologia sempre esteve "míope" diante da realidade social, das necessidades e sofrimento da população, levando os profissionais a cometer muitas distorções teóricas, a práticas descontextualizadas e etnocêntricas e a uma psicologização dos problemas sociais, na medida em que não são capacitados para perceber as especificidades culturais dos sujeitos. (p. 59)

Outras autoras, como Benevides (2005) e Hüning e Guareschi (2007 e 2005a), também problematizam essa tentativa da Psicologia de construir conhecimentos e práticas voltadas para a neutralidade de forma desvinculada da política. Benevides (2005) atenta para um efeito despolitizador trazido por esse olhar cientificista, uma vez que as práticas psicológicas passam a ocupar-se de sujeitos abstratos, retirados de seus contextos sociais, apresentando diferentes questões como referentes ao indivíduo, e não ao coletivo no qual se insere. Hüning e Guareschi (2007) afirmam ainda que é justamente através dos essencialismos e naturalizações que a Psicologia foi se descomprometendo com determinadas práticas, como na formulação de diagnósticos psicológicos, no delineamento de perfis de personalidade, na formulação de categorias psicológicas e, muitas vezes, na própria produção do conhecimento; a partir disso, foi também se distanciando da possibilidade de compreensão dos sujeitos na contemporaneidade, que não podem mais ser inseridos em uma lógica linear e racional, pois emergem em suas multiplicidades.

Essa construção do conhecimento da Psicologia de maneira asséptica e descomprometida é o que tem caracterizado também a formação em Psicologia. Tal formação foi sendo efetivada, majoritariamente, por um olhar tecnicista voltado para o aprendizado da utilização de instrumentos e técnicas que apresentassem respostas corretas e precisas, sem se voltar para uma reflexão sobre a ideia que embasa tais práticas e os efeitos destas no cotidiano dos sujeitos com quem interagem. Dimenstein (2000), ao realizar uma análise acerca dos impasses impostos à inserção do trabalho dos psicólogos no SUS, evidencia que, desde a formação, de um modo geral, os cursos de Psicologia não possibilitam ao aluno o conhecimento dos aspectos sociais, políticos e ideológicos presentes nas relações pessoais e institucionais das práticas psicológicas. Para a autora, trata-se de uma formação que se propõe apolítica e neutra e que, desse modo, se faz ingênua e ineficaz, formando, em sua maioria, profissionais que irão reproduzir acriticamente métodos e procedimentos.

Dessa forma, o que se evidencia na formação e, posteriormente, nas práticas profissionais, 
é a impossibilidade de separação entre Psicologia e política, pois a Psicologia trabalha com sujeitos habitantes de um lugar em determinado momento histórico da sociedade. Diante disso, qualquer intervenção realizada com os sujeitos produz efeitos no coletivo, sempre havendo uma implicação política, pois essa prática é sempre uma ação sobre a vida desses sujeitos. Estar atento a isso é o que vai diferenciar os profissionais que se colocam em uma postura éticopolítica, ou seja, que se comprometem com o cuidado relativo à vida dos sujeitos que afetam. O oposto é a prática de profissionais que acreditam que a ética se expressa no seguimento fiel a um manual, código ou termo de consentimento informado. Essa postura da Psicologia de querer manter uma cientificidade e neutralidade que, inclusive, vão de encontro aos princípios colocados pelo SUS, como, por exemplo, o da integralidade, é o que pode dificultar a produção de outras práticas na promoção de saúde.

Coimbra e Nascimento (2001) fundamentamse em Foucault para mostrar a impossibilidade de as ações da Psicologia serem neutras ou apolíticas, ressaltando que:

Para Foucault (1988), os saberes, compreendidos como materialidade, práticas e acontecimentos, são dispositivos políticos articulados com as diferentes formações sociais, inscrevendo-se, portanto, em suas condições políticas. Daí afirmar que não há saber neutro: todo saber é político. (p. 246)

O que essas autoras querem afirmar é que Foucault denuncia a inexistência de uma essência das coisas, afirmando que os sujeitos com quem a Psicologia trabalha e a própria concepção de Psicologia são construídos historicamente e, portanto, imbuídos de um contexto político (Coimbra \& Nascimento, 2001).

A partir dessa reflexão acerca do distanciamento que historicamente foi se construindo entre Psicologia e política na tentativa de construção de um campo de saber científico, objetiva-se, neste artigo, visualizar os impasses que essa dicotomização provoca na formação de profissionais de Psicologia para trabalhar em políticas públicas, especialmente no que se refere ao Sistema Único de Saúde. Pretende-se evidenciar os contrastes existentes nas demandas ao trabalho de profissionais comprometidos com o cuidado e a promoção de saúde, e não com uma prática orientada a partir da neutralidade e do distanciamento, presentes na forma de se aplicarem os conhecimentos no desenvolvimento das práticas profissionais.

Assim, procuramos evidenciar a formação acadêmica como espaço privilegiado de construção de uma prática que, quanto mais envolvida politicamente, mais próxima estará de efetivar o trabalho na saúde coletiva. Para tanto, situamos, em um primeiro momento, a experiência do estágio em Psicologia no Conselho Regional de Psicologia do Rio Grande do Sul (CRPRS) como parte importante da formação em Psicologia. Em um segundo momento, descrevemos esse estágio, a fim de contextualizá-lo no CRPRS, mais especificamente, no Centro de Referência Técnica em Psicologia e Políticas Públicas (CREPOP) e nas atividades junto ao Controle Social no Conselho Municipal de Saúde de Porto Alegre, e discutir a função deste último como diretriz do SUS. Após isso, problematizamos a formação em Psicologia para as práticas psicológicas no SUS.

Além das vivências do estágio, a construção deste artigo tem como importante atravessamento as ações de pesquisa junto ao grupo Estudos Culturais e Modos de Subjetivação, do Programa de Pós-Graduação em Psicologia da PUCRS, em um exercício constante de reflexão sobre as práticas psicológicas, a produção do conhecimento e a formação em Psicologia, presentes nas discussões e produções do grupo de pesquisa. A questão referente à formação acadêmica vem sendo trabalhada no projeto de pesquisa 
A Psicologia e a Formação do Profissional da Saúde para o SUS: um Estudo a Partir dos Currículos de Cursos de Psicologia do Rio Grande do Sul, que realiza uma análise de currículos dos cursos de Psicologia do Estado do Rio Grande do Sul com o objetivo de visualizar indicativos da formação de profissionais da saúde para o SUS.

\section{A formação acadêmica em Psicologia}

Para o desenvolvimento da discussão sobre a necessidade de o psicólogo se colocar como agente político, é importante destacar alguns tensionamentos presentes na formação acadêmica em Psicologia que emergem a partir desse reconhecimento. Um dos primeiros desafios que se apresentam é o de realizar uma reflexão no sentido de abrir mão de certezas e permitir-se experimentar um lugar de incompletude. Para Nascimento et al. (2006), "não ter um lugar seguro onde se apoiar gera dúvidas, angústias e medos, ao passo que ter acesso, já a partir da graduação, a experiências que reinventem a Psicologia é fundamental para construir autonomia e segurança nas decisões e análises" (p. 16).

Entretanto, como aponta Dimenstein (2001), o que se observa na maioria dos contextos nos quais as práticas psicológicas têm sido questionadas é que elas levam a se pensar que

A formação acadêmica não tem fornecido
elementos para a construção de um
profissional-cidadão com possibilidade
de intervenção adequada aos espaços
territoriais locais, que demandam um alto
grau de potência de resposta/ação, de
articulação intersetorial, de mobilizçãa de
parcerias e de estratégias específicas. (p. 59)

A consequência dessa fragilidade na formação vai ser observada somente mais tarde, quando esses profissionais estão, por exemplo, desenvolvendo atividades no setor público, especialmente nos serviços de saúde. Dados recentes revelam que a área pública em saúde tem surgido como o grande empregador da Psicologia, absorvendo, muitas vezes, aqueles profissionais que não conseguiram se colocar no mercado de trabalho nas áreas de intenção primeira do desejo de trabalhar (Spink, 2003). Assim, podemos pensar que o que leva alguns profissionais a escolherem trabalhar nas políticas públicas não seria um encantamento com seus desafios e a possibilidade de efetiva intervenção política das práticas psicológicas, nem uma compreensão do compromisso social da Psicologia com a saúde coletiva, mas sim, a escassez de vagas ou a dificuldade de montar e sustentar um consultório logo após a formatura. Essa conjuntura na formação e no mercado de trabalho do psicólogo é propícia a um impasse diante da necessidade de superar práticas cristalizadas e de disponibilizar-se às exigências das políticas públicas no que diz respeito à responsabilidade social, aos princípios de qualidade, ética e exercício da cidadania buscados pelo SUS (Dimenstein, 2001).

Diante disso é que consideramos de fundamental importância a experiência de estágio que alguns Conselhos Regionais de Psicologia - através dos Centros de Referência Técnica em Psicologia e Políticas Públicas (CREPOP) - vêm proporcionando para estudantes no término da formação que pretende desenvolver as práticas profissionais no setor público da saúde ou da assistência social, pois, como já apontaram Nascimento et. al. (2006),

participar de um estágio de Psicologia é também participar de fóruns de decisões políticas, é incluir-se na discussão da questão dos direitos humanos, dos movimentos sociais e da produção da violência urbana, retirando o psicólogo do lugar do assistencialismo e do atendimento pontual e envolvendo-o num cotidiano de indagações ético-políticas. (p. 16) 


\section{O Centro de Referência Técnica em Psicologia e Políticas Públicas - CREPOP²}

O CREPOP é uma ferramenta do Sistema Conselhos que foi desenvolvida a partir da necessidade de maior aproximação do Conselho de Psicologia com a atuação profissional do psicólogo junto às políticas públicas. O CREPOP é uma construção coletiva que surgiu como proposta no Congresso Nacional da Psicologia (CNP), tendo recebido aprovação na Assembléia de Políticas Administrativas e Financeiras (APAF). Sua implementação ocorreu no ano 2006. Dentro da estrutura do Sistema Conselhos, o CREPOP é constituído de uma coordenação nacional, ligada à gestão executiva do Conselho Federal de Psicologia, e de unidades locais subordinadas aos Conselhos Regionais. Nos Conselhos Regionais, o CREPOP atua em articulação com a Comissão de Políticas Públicas (CPP). A equipe do CREPOP é formada por um corpo político, composto por um conselheiro de referência, e por um corpo técnico, composto por especialistas no campo das políticas públicas que prestam assessoria aos Centros. Essa constituição é organizada no sentido de garantir o respeito e a manutenção dos interesses da categoria e o desenvolvimento das atividades específicas do CREPOP.

O CREPOP define como um de seus principais propósitos ampliar a atuação dos psicólogos na esfera pública e expandir a contribuição profissional da Psicologia para a sociedade brasileira. Nesse sentido, o CREPOP objetiva sistematizar e difundir os conhecimentos e as práticas psicológicas aplicadas ao setor público estatal, registrar as competências da profissão nesse setor, identificar novas oportunidades de inserção da Psicologia e as limitações presentes na atuação dos profissionais nas políticas públicas, apresentar propostas de ação profissional para as demandas identificadas, construir e disponibilizar referências técnicas para o exercício profissional nesse campo, promover a interlocução da Psicologia com os espaços de formulação, gestão e execução de políticas públicas e promover o desenvolvimento de conhecimentos acerca dessa área de atuação nos meios acadêmico e profissional.

Como estratégia de intervenção, as atividades são definidas em subprojetos, dos quais se destacam o subprojeto Pesquisa Permanente em Políticas Públicas, que objetiva buscar e organizar informações sobre os profissionais ativos na área, documentos, legislação e ações de referência, constituindo bancos de dados e uma biblioteca virtual que são alimentados a partir das demandas identificadas nesse processo tanto pelos técnicos quanto pelos profissionais, através de uma construção coletiva. Esse primeiro subprojeto também dá subsídios para o segundo, intitulado Investigação da Prática Profissional, que tem como intuito identificar as principais estratégias de atuação dos profissionais, as atividades desenvolvidas, os recursos utilizados, os referenciais teóricos, a articulação com a rede de serviços e a demanda atendida, enfim, uma série de informações sobre o cotidiano da prática dos profissionais que atuam em uma determinada área das políticas públicas. As áreas a serem trabalhadas são definidas na APAF, sendo estipuladas pelo período de um ano e tendo como critérios a tradição na Psicologia, a abrangência territorial, o caráter social e emergencial dos serviços e a existência de marcos lógico e legal. Para cada área de investigação, são destinados cerca de dois a três meses para aprofundamento teórico, levantamento de informações junto aos serviços públicos, articulação dos contatos com os profissionais e coleta e sistematização dos dados.

A consulta junto aos profissionais ocorre a partir de três diferentes estratégias de intervenção: um questionário online, respondido pelos 
psicólogos contatados, que fica disponível na internet no site do CREPOP (http:// crepop.org.br) e que abrange questões como contexto de atuação, população atendida, métodos e modos de ação, opiniões sobre a prática profissional e necessidades de mudanças, reuniões específicas que podem constituir um espaço mais amplo, com a participação de autoridades e especialistas da área, equipes dos serviços e profissionais da Psicologia, e grupos focais somente com os psicólogos, com o objetivo de aprofundar e compreender as especificidades da ação desses profissionais no cotidiano do trabalho.

Esses encontros geram relatórios, que são enviados ao Núcleo Nacional do CREPOP e organizados no sentido da elaboração de referências técnicas para os profissionais da área, sendo essas informações devolvidas posteriormente para os psicólogos que participaram do processo e para a categoria como um todo. Esse processo foi estruturado de forma a garantir a participação dos trabalhadores da Psicologia em políticas públicas, para que seja possível construir um material que realmente reflita a realidade da prática profissional. Esse é um trabalho que não se encerra na simples construção das referências e que é entendido como o início de um processo maior a partir do qual podem emergir ações no âmbito das políticas públicas para os Conselhos e para toda a categoria.

No que se refere à garantia das diretrizes políticas relativas aos interesses da categoria, o CREPOP, aliado à Comissão de Políticas Públicas, no que diz respeito ao Conselho Regional de Psicologia do Rio Grande do Sul, atua no sentido de articular as representações do CRP junto às instâncias de Controle Social, participando da promoção de capacitações para os representantes, do levantamento de dados referentes a essas representações no Estado, da sensibilização dos conselheiros e de demais representantes da categoria para a importância desse engajamento e da própria atuação do conselheiro-referência e do assessor técnico junto ao Controle Social, nesse caso, como no Conselho Estadual de Saúde, no Conselho Municipal de Saúde, através da Comissão de Saúde Mental e no Conselho Estadual de Assistência Social. Nos espaços em que tem assento, o trabalho dos representantes do CRP tem sido referenciado e reconhecido, fruto de uma postura engajada e propositiva que vem sendo assumida pelos representantes nas diferentes instâncias do Controle Social. Esse retorno é, em grande parte, resultado do trabalho coletivo da CPP com o CREPOP.

\section{A construção de um espaço de formação: o estágio}

Em consonância com um dos objetivos do CREPOP, o de promover o desenvolvimento de conhecimentos acerca das políticas públicas como área de atuação nos meios acadêmico e profissional, é que foi se estruturando a construção do estágio curricular em Psicologia comunitária. Já idealizado desde 2007, mas somente iniciado em março de 2008, o CREPOP do CRPRS foi pioneiro na iniciativa de construção de uma proposta de estágio curricular, que foi posteriormente reconhecida e regulamentada pelo Núcleo Nacional do CREPOP. Embora inicialmente o estágio tenha sido formulado e desenvolvido com enfoque voltado para uma área da Psicologia comunitária, esse espaço também pode ser trabalhado dentro da perspectiva do que vem sendo denominado estágio ampliado ou integrado, que abrange a discussão sobre as diferentes práticas psicológicas de maneira transversal.

Como objetivos, definem-se: possibilitar a formação do estudante no aprendizado das áreas de trabalho na rede pública em relação à gestão, à intersetorialidade, aos serviços e ao controle social, promover maior aproximação do estudante de Psicologia com as atividades dos Conselhos Regional e Federal 
de Psicologia, possibilitar o aprendizado de uma visão ampliada da atuação da Psicologia nos mais diversos serviços destinados ao atendimento da população na rede pública local e nas suas interfaces, oportunizar ao estagiário a experiência de atuação junto às instâncias de Controle Social, podendo discutir questões pertinentes à realidade dos serviços do Sistema Único de Saúde, da rede de serviços substitutivos proposta a partir da reforma psiquiátrica e da legislação e das normativas que orientam e sustentam as práticas dos profissionais e seu compromisso social, além de contribuir para o desenvolvimento de um olhar crítico das práticas profissionais e de um posicionamento político frente à realidade.

Dentre as atividades desenvolvidas para contemplar os objetivos traçados, destacase a participação nos subprojetos Pesquisa Permanente em Políticas Públicas e Investigação da Prática Profissional, que envolve desde a busca de materiais teóricos sobre as áreas de especificação da pesquisa e a participação em eventos científicos voltados para as temáticas até o contato com as principais autoridades do campo e com os profissionais de todo o Estado. Além disso, realizam-se visitas aos serviços contatados, podendo-se ter uma noção mais ampla do cotidiano de trabalho. Também é feito o trabalho de sensibilização e de organização dos encontros dos grupos de profissionais de cada área. Por fim, há a realização dos relatórios que darão origem às referências técnicas. Paralelamente a essas atividades, estão as de participação no Controle Social, através do acompanhamento das atividades da Comissão de Saúde Mental do Conselho Municipal de Saúde, na qual o Conselho Regional de Psicologia atua como representante da categoria no segmento trabalhador.

No que diz respeito à composição dessa representação do CRP, é interessante destacar que o Conselho de Psicologia, bem como os demais Conselhos profissionais, é considerado uma autarquia federal. Em sua fundação, é colocado ao lado dos serviços públicos. Isso acontece porque os Conselhos profissionais foram criados no período ditatorial do Brasil, com o intuito de controlar e fiscalizar os profissionais. Esse caráter repressivo começa a ser modificado a partir do Primeiro Congresso Nacional de Psicologia. Embora seja complexo realizar esse deslocamento, a criação do CREPOP, em 2006, é uma estratégia que vem possibilitando a construção de diálogo com a categoria, no intuito de propor que a Psicologia desenvolva um novo olhar em relação aos compromissos com os direitos humanos e com as políticas públicas.

\section{O Controle Social e as políticas públicas de saúde}

Refletir sobre as questões que se colocam ao Controle Social se faz necessário para se poder pensar o quanto estão relacionadas à formação acadêmica. É vital poder colocar em debate o papel que a Academia vem exercendo na formação de profissionais para o SUS, a partir dos efeitos que se observam dentro das instâncias de participação social. Além disso, é importante realizar alguns apontamentos de iniciativas passíveis de desestabilização no impasse que vem se construindo entre a formação acadêmica e a demanda profissional no SUS.

A denominação Controle Social, como trabalhado aqui, surge na $9^{a}$ Conferência Nacional de Saúde, de 1992, sendo entendido como o processo de formulação, gestão e avaliação das políticas sociais e das atividades desenvolvidas com a seguridade social pela população. Na área da saúde, significa dizer que o Controle Social é o direito e o dever da sociedade de participar dos debates e decisões bem como da formulação, execução e avaliação das políticas de saúde nos diferentes âmbitos de governo (Ceccim \& Feuerwerker, 2004). 
No que se refere à estrutura do SUS, as atividades do Controle Social são o que garante a efetivação de uma das diretrizes do sistema, a da participação social, definida como:

uma das maneiras de se efetivar a democracia, por meio da inclusão de novos sujeitos sociais nos processos de gestão do SUS como participantes ativos nos debates, formulações e fiscalização das políticas desenvolvidas pela saúde pública brasileira, conferindo-lhe legitimidade e transparência. Com previsão constitucional e legal, a participação popular confere à gestão do SUS realismo, transparência, comprometimento coletivo e efetividade de resultados. Está diretamente relacionada ao grau de consciência política e de organização da própria sociedade civil. O SUS deve identificar o usuário como membro de uma comunidade, com direitos e deveres, e não como receptor passivo de benefícios do Estado. (Brasil, 2004).

O Controle Social em saúde possui dois dispositivos previstos em lei para a participação da sociedade, que são os Conselhos de Saúde e as Conferências de Saúde. As Conferências são realizadas de quatro em quatro anos, aproximadamente, e têm como objetivo criar diretrizes para o funcionamento dos serviços de saúde do SUS. Os Conselhos de Saúde são organismos colegiados de caráter deliberativo e permanente que atuam na elaboração de estratégias e no controle da execução da política de saúde (Arantes, Mesquita, Machado, \& Ogata, 2007). Este artigo manterá seu foco nos Conselhos de Saúde, uma vez que estes foram estruturados a partir da participação no Conselho Municipal de Saúde, mais especificamente, na Comissão de Saúde Mental.

Para Sposati e Lobo (1992),

O Controle Social é, na história de democratização das políticas de saúde, um dos campos que construiu visibilidade aos movimentos de saúde, quer pela denúncia das 'ausências e omissões' dos serviços instalados, quer pela luta em construir um espaço regular para o exercício do controle dos serviços e nas burocracias de gestão de saúde. (p. 366)

No entanto, desde a regulamentação dos Conselhos de Saúde pela Constituição de 1988 e da formulação do Sistema Único de Saúde, permanece a dificuldade de efetivação da participação popular e da legitimação desses espaços com sua formação paritária entre representantes dos usuários (50\%), dos trabalhadores de saúde (25\%) e de gestores e prestadores de serviço (25\%). Nesse sentido, um dos desafios ainda presentes é o de fazer com que as leis deixem de ser apenas instrumentos formais e passem a ter aplicação efetiva. Para isso, é preciso que os representantes das lutas populares estejam instrumentalizados e orientados para construir uma pressão pela mudança da situaçãoproblema (Sposati \& Lobo, 1992).

Outro ponto que se coloca e que neste momento parece emergir como fundamental para o desenvolvimento desta reflexão é que a saúde precisa ser vista mais como um direito e menos como um serviço, principalmente dentro das discussões que perpassam os Conselhos de Saúde. Muitas vezes, os representantes da sociedade civil atuam como consumidores que estabelecem um entrave junto a seus fornecedores, os gestores.

Segundo Sposati e Lobo (1992), essa questão é ainda mais complexa, pois:

para funcionar na plena lógica de mercado, o "produto saúde" deveria ser uma necessidade de consumo individual, cuja satisfação seria uma questão de gosto e de estilo, e não só de necessidade. Porém, saúde, que é uma questão de vida individual e coletiva, exige um padrão público e social. Isso supõe entendê-la não como um produto a ser consumido, mas, sobretudo, delinear o projeto que se quer 
como padrão de qualidade de vida de uma sociedade e, nela, de cada um dos cidadãos.

(p. 367, itálicos das autoras)

Como algo vendável, a saúde é vista através de produtos, como medicamentos, tratamentos, instrumentos, aparelhos, planos de saúde, etc. Em uma formação voltada para a clínica privada, a saúde mental é tida como um produto a ser consumido e pago. Não é por acaso que, junto ao plano de tratamento, descreve-se a importância da ação de pagamento da consulta, traduzida na valorização e no comprometimento do paciente com o processo terapêutico.

O que Sposati e Lobo defendem é que o "direito à saúde é mais do que o direito ao consumo de saúde" (p. 367). Para as autoras, sem essa concepção, acaba-se por naturalizar a doença e as carências, pois elas são as demandas de mercado a serem supridas. Não se quer negar o fato de que, para a efetivação da saúde como direito, é preciso que haja serviços de saúde qualificados, no entanto, não se pode perder de vista que essa noção vai além da simples discussão dos serviços. Deve-se pensar em que lógica essa discussão está pautada - se é na lógica do consumo ou na do direito.

O problema é que, diante da ausência de uma lei federal que regulamente o direito à saúde, faltam parâmetros claros que instrumentalizem o controle por parte da população. Da forma como está posto esse direito hoje, os Conselhos de Saúde veem-se, muitas vezes, dependentes da boa vontade dos gestores e de políticas que se tornam instáveis e inefetivas com as trocas de gestões. Com um Controle Social instrumentalizado, informado e politicamente ativo, não se permitiria um aniquilamento das iniciativas realizadas pelo governo anterior, mas ter-seia a obrigatoriedade de implementação dos serviços, não por boa vontade ou por uma dita responsabilidade para com o povo, não como um favor ou assistencialismo, mas por um direito reconhecido da população.
Dentro da perspectiva do estágio curricular, a participação em um espaço como esse do Controle Social traz em si um aprendizado que, para o aluno, representa um comprometimento político com as ações em saúde, afirmando posicionamentos, repensando práticas e o próprio SUS. Além disso, o estagiário se insere em um contexto transdisciplinar e intersetorial.

\section{As práticas psicológicas em saúde e a formação em Psicologia}

Para se poder avaliar a formação em Psicologia nas práticas em saúde coletiva e em questões que emergem nas ações de Controle Social, principalmente no que diz respeito à forma como a Psicologia tem experienciado a participação nas equipes profissionais e o compromisso social junto ao SUS, é preciso situar como a Psicologia passa a fazer parte da área da saúde, isso porque esse lugar não pertenceu sempre à Psicologia, não podendo ser visto de forma naturalizada. Foi em um determinado momento histórico que a Psicologia passou a produzir práticas e concepções teóricas a respeito da saúde.

A inserção da Psicologia no cuidado à saúde das populações se deu a partir de dois focos principais: a saúde do trabalhador e a saúde materno-infantil. Com isso, a área passou a incrementar o desenvolvimento de instrumentos, práticas e saberes que, com a Medicina social, colaboraram no estudo epidemiológico de identificação de patologias e doenças descritivas e na identificação de grupos de risco e de populações vulneráveis, características centrais na perspectiva de saúde higienista (Spink, 2003). Dessa forma, a Psicologia, através dos testes e da avaliação psicológica, teve sua entrada para o âmbito da saúde fortemente estruturada em um modelo biologicista, através da identificação de distúrbios e transtornos, com uma atenção focada principalmente na compreensão e 
no tratamento de doenças. No entanto, foi de dentro da própria Psicologia que emergiram rupturas no modo de edificação desse campo de saber como ciência e profissão. Um movimento no intuito de abarcar as diversidades e multiplicidades dos sujeitos e de seus modos de interagir com o mundo, não reduzindo o sujeito aos aspectos biológicos, foi protagonizado pela Psicologia social e comunitária e pela Psicologia do trabalhador e saúde mental (Jacques, 2005).

Nesse sentido, o que marca o reconhecimento não só da Psicologia e das demais disciplinas das ciências humanas, como assistência social, Sociologia, terapia ocupacional, e também o dos profissionais de educação física, artes plásticas, artes cênicas e música, é a constituição do Sistema Único de Saúde. Essas profissões são convidadas a compor o quadro de profissionais do SUS, na tentativa de dar conta de uma demanda construída a partir da concepção de saúde pautada não mais na simples ausência de doença, mas na promoção das condições de vida dos sujeitos, lançando-se um olhar integral que abarque os diversos contextos em que estão inseridos.

De acordo com o que propõe a política do SUS, a integralidade representa muito mais do que a soma de olhares especializados; ela só se efetiva através da composição de um trabalho em equipes transdisciplinares. A construção de uma proposta como essa exige a desconstrução das barreiras das especificidades das áreas do conhecimento e o rompimento também de outras, ainda mais fortemente constituídas: as fronteiras identitárias.

A Psicologia tem sua identidade marcada através da construção de seu objeto de estudo: a interioridade dos sujeitos. Ao produzir saberes acerca dessa interioridade, reserva para si o conhecimento sobre os modos de acesso à existência dos sujeitos
(Dimenstein, 2000) e, ao mesmo tempo, afasta a possibilidade de que outras áreas do conhecimento se apropriem desse saber, como forma de manter uma identidade por meio da qual o psicólogo possa se reconhecer como tal. Outra questão que está presente na delimitação das fronteiras identitárias é a identificação dos testes psicológicos como aquilo que confere identidade à profissão, uma vez que são de uso exclusivo do psicólogo, de acordo com o Art. 4음o Decreto no. 53.464, de 21 de novembro de 1964, que define que: são funções do psicólogo utilizar métodos e técnicas com o objetivo de diagnóstico psicológico, orientação e seleção profissional, orientação pedagógica e solução de problemas de ajustamento. Aliado a isso, há a noção de que os testes conferem cientificidade à Psicologia, através da experimentação de forma objetiva e quantitativa que atribui à Psicologia o mesmo status científico das ciências naturais e exatas.

Aqui dois pontos são evidenciados, ao longo da formação da Psicologia como ciência e profissão, como impasses para a atuação do profissional da Psicologia no SUS. O primeiro está relacionado à necessidade de demarcação de uma identidade profissional, e o segundo, à emergência dos testes de avaliação psicológica e psicométricos como possibilidade de construção dessa identidade, estando esses instrumentos ao lado da perspectiva de manutenção de um caráter científico e de busca de identificação de comportamentos normais e desviantes. As práticas psicológicas, portanto, colocam-se distantes da perspectiva da promoção de saúde, que não identifica o diagnóstico como condição primeira e fundamental para as ações em saúde.

Além do individualismo que se reflete na dificuldade de ultrapassar as fronteiras identitárias, permitindo uma integração de saberes na composição das equipes de saúde, existe outra questão que perpassa o fazer em Psicologia junto ao SUS que está intimamente relacionada às anteriores: a necessidade de 
um posicionamento ético/político que se impõe na relação com seu objeto de estudo, isto é, com os sujeitos. Para que se possa compreender um indivíduo de forma integral, é preciso reconhecer que ele está situado em um determinado contexto histórico e social. Nesse sentido, fazer Psicologia é permitir-se entrar em contato com o outro, é estar envolvido naquilo que compõe suas condições de vida, o que pressupõe responsabilidade pela criação de estratégias de modificação da realidade dos sujeitos, especialmente no que diz respeito à noção de garantia de direitos. Essa perspectiva de comprometimento com o outro coloca em xeque as concepções de distanciamento e neutralidade assumidas pela Psicologia na sua construção como ciência que ainda se veem presentes no ensino das práticas na formação acadêmica (Benevides, 2005). Nas atividades do estágio que se referem ao acompanhamento das reuniões da Comissão de Saúde Mental do CMS, o que se evidencia é que o Controle Social é um trabalho efetivado através desses dois pontos fundamentais: o da troca, da composição de saberes entre seus membros, atravessado pela perspectiva da transdisciplinaridade, e o segundo, o da prática de uma psicologia politicamente comprometida, sabedora de seu compromisso social.

A formação acadêmica pode ser um espaço privilegiado de construção de profissionais capazes de pensar a respeito das práticas que realizam, profissionais que se lançam ao exercício de reflexão sobre a extensão das ações em Psicologia, principalmente daquelas vivenciadas nas atividades de estágio curricular. A necessidade de repensar a Psicologia parece estranha àqueles que a enxergam ainda através da lente da Modernidade, em que, conforme Hüning e Guareschi (2005b), "os chamados conhecimentos científicos sempre operaram e ainda operam como ferramentas centrais: eles constituem categorias, classificam, ordenam e determinam os lugares certos para cada coisa" (p. 90). Assim, para uma psicologia da ciência da neutralidade, faz sentido que o ensino seja voltado para o aprendizado preciso e profundo de técnicas e instrumentos que traduzam essa suposta objetividade. No entanto, essa formação, quando colocada de frente com a multiplicidade de contextos e sujeitos da contemporaneidade, repletos de demandas nunca lidas nos livros e que, no serviço público, surgem com ainda mais força, acaba se deparando com a pouca eficiência de seus instrumentos e técnicas. Isso ocorre porque estes estão fundamentados ainda na ideia do não envolvimento, trabalhando com sujeitoNa pesquisa citada anteriormente, desenvolvida pelo grupo de pesquisa Estudos Culturais e Modos de Subjetivação, que analisa o currículo de seis cursos de Psicologia do Rio Grande do Sul no que se refere às disciplinas mais diretamente relacionadas à saúde, em cinco dos seis cursos analisados, cerca de $60 \%$ das disciplinas selecionadas estão relacionados ao ensino de conteúdos voltados para a compreensão das psicopatologias e da avaliação psicológica; outros 15\%, em média, estão direcionados para os conteúdos da área das biomédicas; somente cerca de $25 \%$ estão voltados para as disciplinas de Psicologia social e comunitária. Há a exceção de um único curso, em que as três áreas absorvem quase igualitariamente as disciplinas; no entanto, esse curso também apresenta em pequena vantagem os conteúdos da primeira área. Isso evidencia que a formação em Psicologia no Estado do Rio Grande do Sul, de um modo geral, ainda privilegia o ensino de testes de avaliação psicológica e de técnicas de psicodiagnóstico. Nesse sentido, é importante ressaltar a criação e a promoção de espaços de rupturas na lógica de busca de uma cientificidade traduzida em instrumentos e técnicas que deem respaldo a esse lugar de saber, como o que tem acontecido em algumas experiências de estágio, como essa do Conselho Regional de Psicologia através do CREPOP. 
Com isso, deve-se reafirmar que é impossível pensar em "práticas dos psicólogos que já não estejam diretamente comprometidas com o mundo e com o país onde vivemos, com as condições de vida da população brasileira, com o engajamento na produção de saúde" (Benevides, 2005, p. 23). Fala-se aqui de um profissional (não isento) inundado de subjetividades, (não separado) misturado à ação política, que (não se distancia) se aproxima dos sujeitos a ponto de, muitas vezes, conhecer o cheiro de suas casas, que entende que as técnicas e instrumentos devem ser colocados a favor de sua práxis e que não deve se tornar escravizado por eles.

Portanto, é preciso, desde a formação acadêmica, construir um pensamento crítico em relação às próprias práticas da Psicologia, em relação à produção de subjetividades dentro dos diferentes contextos, compreendendo que essa é uma construção que se faz a partir de um determinado tempo e de um determinado lugar; sendo assim, é sempre uma construção política. Diante desse reconhecimento, é preciso assumir um compromisso ético com a produção de saúde dos sujeitos com quem o profissional trabalha.

Além disso, o que se evidencia neste trabalho é a importância dos espaços de Controle Social para a promoção da cidadania e a garantia dos direitos, observando-se que eles precisam fazer-se efetivos nesse propósito. Uma das estratégias de qualificação dessa ação é trabalhar essas discussões desde a graduação, uma vez que "o compromisso social requer um sujeito capaz de constituir um saber crítico sobre si mesmo, sobre seu mundo e sobre sua inserção nesse mundo" (Dimenstein, 2001, p. 59).

Essas reflexões podem estar potencializadas na formação, entendendo-se qual é o lugar da Psicologia dentro do SUS e para onde e de que forma pretendemos representar a Psicologia em nossa atuação futura. É mais do que aprender técnicas de tratamento, é poder compreender toda a complexidade que envolve o conceito de saúde e responsabilizarse pela efetivação desta como um direito. É mais do que ver os contextos sociais; é deixarse tocar por eles. É mais do que somente se sentir penalizado pelas deficiências da saúde pública, é colocar-se a serviço de uma ação política que provoque mudanças. Como exemplificado no diálogo reproduzido no início do artigo, avaliar as práticas psicológicas no SUS é mais do que entender o que o Controle Social tem a ver com a Psicologia - é conseguir compreender que a Psicologia sempre vai estar politicamente envolvida.

Nesse sentido, a experiência de estágio dentro do CREPOP emerge como uma das escassas possibilidades de criação de uma perspectiva diferenciada para a formação acadêmica que se aproxime desse debate. É uma proposta construída no intuito de abrir um diálogo que leve para dentro das instituições de ensino - através das supervisões acadêmicas, das trocas de vivências com os colegas de curso, das produções que surgem da prática do estágio e do próprio estagiário - as problemáticas debatidas no Controle Social e nos relatos e visitas a lugares que nos colocam em contato com a vivência cotidiana dos profissionais das diferentes áreas das políticas públicas. Além disso, é sempre um convite a repensar as práticas desenvolvidas e sua intencionalidade, da mesma forma como é fundamental repensar o processo a partir do qual nos formamos psicólogos. 


\section{Carolina dos Reis}

Mestranda em Psicologia Social e Institucional do Grupo de Pesquisa Estudos Culturais e Modos de Subjetivação do PPGPSI da UFRGS, Rio Grande do Sul, RS - Brasil.

\section{Neuza Maria de Fátima Guareschi}

PhD EDUCATION - UNIVERSITY OF MADISON WISCONSIN

Docente do Programa de Pós-Graduação em Psicologia Social e Institucional da Universidade Federal do Rio Grande do Sul, Coordenadora do Grupo de Pesquisa Estudos Culturais e Modos de Subjetivação.

E-mail: nmguares@gmail.com

\section{*Endereço para envio de correspondência:}

Av. Grécia, 1100/1205, Bairro Passo D’Areia, Porto Alegre, Rio Grande do Sul - RS - Brasil CEP 91350070.

E-mail: carolinadosreis@gmail.com

Recebido 28/10/2008, 1a Reformulação 27/11/2009, Aprovado 29/4/2010.

Referências

Arantes, C. I. S., Mesquita, C. C., Machado, M. L. T., Ogata, M. N. (2007). O controle social no Sistema Único de Saúde: concepções e ações de enfermeiras da atenção básica. Texto contexto - Enfermagem, 16(3), 470-478.

Benevides, R. (2005). A psicologia e o Sistema Único de Saúde: quais interfaces? Psicologia e Sociedade, 17(2), 21-25.

Brasil. Ministério da Saúde. (2004). Sus de A a Z. Recuperado em setembro de 2008, de http://dtr2004.saude.gov.br/susdeaz/

Ceccim, R., \& Feuerwerker, L. (2004). O quadrilátero da formação para a área da saúde: ensino, gestão, atenção e controle social. Physis: Saúde Coletiva, 14(1), 41-65.

Centro de Referência Técnica em Psicologia e Políticas Públicas. (2008). Conheça o CREPOP. Recuperado em setembro de 2008, de http://crepop.pol.org.br/publique/cgi/cgilua.exe/ sys $/$ start.htm $?$ infoid $=695 \&$ sid $=31$

Coimbra, C., \& Nascimento, M. L. (2001). O efeito Foucault: desnaturalizando verdades, superando dicotomias. Psicologia, Teoria e Pesquisa, 17(3), 245-248.

Conselho Federal de Psicologia. (2008). Sistema Conselhos. Recuperado em setembro de 2008, de http://www.pol.org. $\mathrm{br} / \mathrm{pol} / \mathrm{cms} / \mathrm{pol} / \mathrm{sistema}$ conselhos/

Conselho Regional de Psicologia. (2008). Orientação e legislação. Recuperado em setembro de 2008, de http://www.crprs.org. br/orientacao_leis_decretos.php

Dimenstein, M. (2000). A cultura profissional do psicólogo e o ideário individualista: implicações para a prática no campo da assistência pública à saúde. Estudos de Psicologia, 5(1), 95-121.
Dimenstein, M. (2001). O psicólogo e o compromisso social no contexto da saúde coletiva. Psicologia em Estudo, 6(2), 57-63.

Foucault, M. (1998). Microfísica do poder (R. Machado, trad.). Rio de Janeiro: Graal.

Hüning, S., \& Guareschi, N. (2005a). Efeito Foucault: desacomodar a psicologia. In S. Hüning \& N. Guareschi (Eds.), Foucault e a psicologia (pp. 107-127). Porto Alegre: Abrapso Sul.

Hüning, S., \& Guareschi, N. (2005b). O que estamos construindo: especialidades ou especialismos? Revista Psicologia e Sociedade, 17(1), 89-92.

Hüning, S., \& Guareschi, N. (2007). Implicações da psicologia no contemporâneo. In S. Hüning \& N. Guareschi (Eds.), Implicações da psicologia no contemporâneo (pp. 13-24). Porto Alegre: Edipucrs.

Jacques, M. da G. (2005). Psicologia, trabalho e saúde: uma revisão crítica. Revista de Psicologia, 23(1), 13-22.

Nascimento, M. L., Manzini, J., \& Bocco, F. (2006). Reinventando as práticas Psi. Psicologia e Sociedade, 18(1), 15-20.

Spink, M. J. (2003). Psicologia social e saúde: práticas, saberes e sentidos. Petrópolis, RJ: Vozes.

Sposati, A., \& Lobo, E. (1992). Controle social e políticas de saúde. Cadernos de Saúde Pública, 8(4), 366-378. 